\title{
Инновационные технологии как основа устойчивого развития дорожного строительства
}

\section{Сайфуллина Ф.М. ${ }^{1}$, Мустафина Л.Р. ${ }^{1}$, Семенов Д.Н. ${ }^{1}$}

${ }^{1}$ Казанский государственный архитектурно-строительный университет, Казань, Россия

\begin{abstract}
АННОТАЦИЯ:
На сегодняшний день проблемы определения новых стратегических целей и направлений инновационного развития, ориентированных на преодоление различных барьеров на пути к построению инновационной экономики и создание условий для развития дорожного строительства, очень актуальны. Вопрос применения инноваций является одним из важных условий развития дорожной отрасли, инструментом снижения издержек отрасли и повышения потребительских свойств автомобильных дорог. Результаты исследований, изложенные в статье, применимы при принятии обоснованных решений при планировании стратегически важных вопросов хозяйствования, а также для изучения проблем функционирования предприятий дорожного строительства в современных условиях.
\end{abstract}

КЛЮЧЕВЫЕ СЛОВА: инновации, инновационные технологии, дорожно-строительный комплекс, дорожные покрытия.

Innovative technologies as a basis for sustainable road construction

Sayfullina F.M. ${ }^{1}$, Mustafina L.R. ${ }^{1}$, Semenov D.N. ${ }^{1}$

${ }^{1}$ Kazan State University of Architecture and Engineering, Russia

\section{Введение}

$\mathrm{P}$ азвитие транспортной системы страны становится в настоящее время необходимым условием реализации инновационной модели экономического роста Российской Федерации и улучшения качества жизни населения $[4,11]$ (Guzhov, 2013; Klescheva, 2015). На первое место выдвигаются задачи повышения скорости, удобства и безопасности движения, инженерного оборудования и обустройства, архитектурноэстетического оформления и другие задачи, составляющие комплекс эксплуатационного содержания дорог.

Дорожное строительство как никакая другая отрасль имеет выраженный инфраструктурный характер [5, 6] (Dudin, Tolmachev, 2017; Zhukov, Ilyin, 2017). Специфика отрасли состоит в распространении результатов ее деятельности на все виды вновь создаваемых и обновляемых основных фондов и производственных мощностей, возводимых 
зданий, сооружений и комплексов самого различного назначения. Развитие никакой другой отрасли экономики просто невозможно без строительства дорог.

Совершенствование действующей и создание качественно новой нормативно-правой базы технического регулирования, стандартизации, сертификации и цивилизованного рынка строительных и профильных эксплуатационных услуг в Российской Федерации - актуальная задача, тесно связанная с развитием дорожно-строительного комплекса в целом и его социальной составляющей в частности [3, 17, 21] (Gimadieva, 2017; Rozhkov Zaynullina, 2016; Shagiakhmetova, Mukharramova, Kafiatullina, 2017). Сегодня, когда перед строителями стоят принципиально новые, сложные и высокотехнологичные задачи: освоение подземного пространства мегаполисов, энергетическая эффективность и ресурсосбережение [16] (Rakhmatullina, 2015), экологическая безопасность и охрана окружающей среды [10] (Klescheva, 2017), использование нанотехнологий в производстве инновационных строительных материалов [9] (Ilyina, Kurzina, 2017), проектирование «интеллектуальных» объектов, защита от терроризма, комплексная техническая и конструктивная безопасность в условиях чрезвычайных ситуаций, как никогда актуальными становятся вопросы, связанные с качеством всех уровней подготовки и профессиональной переподготовки кадров, которым предстоит решать задачи из области государственных приоритетов федерального уровня уже сейчас [1] (Abdukhanova, Kulkov, 2017).

\section{Проблемы современных дорожных покрытий}

В процессе эксплуатации автомобильные дороги и дорожные сооружения подвергаются многолетнему и многократному воздействию движущихся автомобилей и при-

\section{ABSTRACT:}

Today, the problems of defining new strategic goals and directions of innovative development, focused on overcoming various barriers to building an innovative economy and creating conditions for the development of road construction are very relevant. The issue of innovation is one of the important conditions for the development of the road industry, a tool to reduce the costs of the industry and improve consumer properties of roads. The research results presented in the article are applicable for making informed decisions during planning strategically important economic issues, as well as to study the problems of functioning of road construction enterprises in modern conditions.

KEYWORDS: innovations, innovative technologies, road-building complex, pavements

JEL Classification: 031, 032, 033

Received: 14.10.2018/ Published: 30.12.2018

(C) Author(s) / Publication: CREATIVE ECONOMY Publishers

For correspondence: Sayfullina F.M. (ufk22abk.ru)

\section{CITATION:}

Sayfullina F.M., Mustafina L.R., Semenov D.N. (2018) Innovatsionnye tekhnologii kak osnova ustoychivogo razvitiya dorozhnogo stroitelstva [ Innovative technologies as a basis for sustainable road construction]. Voprosy innovatsionnoy ekonomiki. 8. (4). - 705-714. doi: 10.18334/vinec.8.4.39612 
родно-климатических факторов [12] (Lapin, 2016). В развитых странах условием реализации инновационной модели экономического роста [2, 7] (Belay, Mukhametzyanova, 2014; Zagidullina et al., 2017) существует прямая зависимость между плотностью автомобильных дорог и национальным доходом на душу населения. Протяженность дорог в этих странах на миллион жителей в 59 раз выше, чем в странах с низкими показателями.

В настоящее время, по оценкам Росавтодора [20], общая протяжённость российской сети автодорог федерального, регионального и местного значения составляет 1396000 км (в том числе около 984000 км с твёрдым покрытием). По данным на сентябрь 2016 года, стандартам качества не соответствуют 62\% региональных дорог (в 2007 году - 56\%). Как отмечают в Минтрансе [14], по федеральным трассам в ненормативном состоянии лишь треть дорог, однако надо учитывать, что доля таких трасс составляет всего около $4 \%$.

Так, по оценкам экспертов, потери нашей страны, обусловленные неразвитостью и низкой пропускной способностью автодорог, составляют более 3\% ВВП, что в 6 раз выше, чем в странах Евросоюза. Низкий технический уровень дорог обуславливает высокий уровень транспортной составляющей в себестоимости продукции и высокую себестоимость перевозок. Для России, где среднее расстояние перевозки грузов в 2-3 раза выше, чем во многих других странах, это губительно для экономики.

Проблемы современных дорожных покрытий [11] (Klescheva, 2015) связаны как с климатическими особенностями, так и устаревшими нормативами и технологиями ГОСТа, существующего более 75 лет. Долгое время в России при возведении дорожного полотна использовался асфальтовый бетон, изготавливаемый в соответствии со стандартом ГОСТа 9128. Существуют разные его марки, отличающиеся как по содержанию компонентов, так и по физико-механическим показателям. Однако с течением времени материалы, изготовленные по нормам нескольких десятилетий назад, уже не справляются с задачами сегодняшнего дня, поэтому требуются новые подходы для повышения коэффициента качества дорог. Также, по мнению ученых, одной из причин быстрого разрушения дорожного покрытия является старение

\section{ОБ АВTOPAX:}

Сайфуллина Фарида Маратовна, доцент кафедры экспертизы и управления недвижимостью, кандидат экономических наук (ufk22abk.ru)

Мустафина Лилия Расиловна, доцент кафедры экономики и предпринимательства в строительстве, кандидат экономических наук, доцент (belliqdyandex.ru)

Семенов Дмитрий Николаевич, магистр 3 курса, направленность (профиль) «Судебная строительно-техническая и стоимостная экспертизы объектов недвижимости»

\section{ЦИТИРОВАТЬ СТАТЬЮ:}

Сайфуллина Ф.М., Мустафина Л.Р., Семенов Д.Н. Инновационные технологии как основа устойчивого развития дорожного строительства // Вопросы инновационной экономики. - 2018. - Том 8. - № 4. С. 705-714. doi: 10.18334/vinec.8.4.39612 
битума, что в результате приводит к трещинам и образованию колейности на дорогах. Единственный путь повысить качество битума в России - применять модифицированный битум на основе различных добавок (полимеров, адгезионных составляющих). Однако стоимость асфальта с использованием битума, модифицированного полимером, увеличивается в среднем на $30-40 \%$, а это, как правило, не находит соответствующего отражения в проектах и сметной документации заказчика, который не готов идти на значительное увеличение стоимости работ.

\section{Современное состояние дорожно-строительного комплекса РТ}

Ежегодно в России ремонтируется от 8000 до 9000 км федеральных трасс и искусственных сооружений на них. По состоянию на 1 января 2017 года протяженность региональных автомобильных дорог в Татарстане составляет 13,5 тыс. км (табл. 1).

Протяженность региональных автодорог, не отвечающих нормативным требованиям, составляет 7274 км (54,2\%). При этом доля дорог, обслуживающих автомобильные потоки в режиме перегрузки, по итогам 2016 года составила почти 228 км. Ежегодно на строительство, реконструкцию, ремонт и содержание автомобильных дорог из республиканского бюджета направляются значительные средства. Причем порядка 80\% всех средств идет на ремонт, содержание и только $20 \%$ предназначаются для прокладки автомагистралей (рuс. 2).

Таблииа 1

Протяженность региональных дорог общего пользования в РТ

\begin{tabular}{|c|c|c|c|c|}
\hline Дата & \multirow{2}{*}{ Всего } & \multicolumn{3}{|c|}{ В том числе } \\
\cline { 3 - 5 } & & $\begin{array}{c}\text { С усовершенствованным } \\
\text { типом покрытия }\end{array}$ & $\begin{array}{c}\text { С переходным типом } \\
\text { покрытия }\end{array}$ & Грунтовые \\
\hline 2012 & $13521 \mathrm{kM}$ & 10946 & 1690 & 884 \\
\hline 2013 & $13561 \mathrm{kM}$ & 11114 & 1630 & 833 \\
\hline 2014 & $13380 \mathrm{kM}$ & 11027 & 1532 & 820 \\
\hline 2015 & $13426 \mathrm{KM}$ & 11401 & 1314 & 709 \\
\hline 2016 & $13436 \mathrm{kM}$ & 11401 & 1335 & 696 \\
\hline 2017 & $13459 \mathrm{KM}$ & 11450 & 1341 & 667 \\
\hline
\end{tabular}

Источник: [15].

В настоящее время в республике реализуется госпрограмма «Развитие транспортной системы Республики Татарстан на 2014-2022 годы» ${ }^{1}$ (показатели реализации представлены в табл. 2). За 2013-2016 годы расходы регионального бюджета на дорожное хозяйство превысили 90782 млн руб. (рuс. 1).

\footnotetext{
${ }^{1}$ Государственная программа «Развитие транспортной системы Республики Татарстан на 20142022 годы», утвержденная постановлением Кабинета Министров Республики Татарстан от 20 декабря 2013 года № 1012.
} 
Таблица 2

\section{Показатели реализации госпрограммы «Развитие транспортной системы Республики Татарстан на 2014-2020 годы»}

\begin{tabular}{|l|c|c|c|c|c|}
\hline \multirow{2}{*}{ Наименование индикатора, ед. измерения } & \multicolumn{5}{|c|}{ Значение показателя } \\
\cline { 2 - 6 } & 2013 год & \multicolumn{2}{|c|}{2014 год } & \multicolumn{2}{|c|}{2015 год } \\
\cline { 2 - 6 } & Факт & План & Факт & План & Факт \\
\hline $\begin{array}{l}\text { Доля дорог регионального значения РТ, не отве- } \\
\text { чающих нормативных требованиям,\% }\end{array}$ & 54,3 & 54,2 & 54,2 & 54,1 & 54 \\
\hline $\begin{array}{l}\text { Удельный вес населенных пунктов, имеющих } \\
\text { дороги с твердым покрытием до сети путей } \\
\text { сообщения общего пользования,\% }\end{array}$ & 75,7 & 77,6 & 77,9 & 78,4 & 79,9 \\
\hline $\begin{array}{l}\text { Отношение дорог с асфальтобетонным покры- } \\
\text { тием к общей протяженности дорог общего } \\
\text { пользования (федерального и регионального } \\
\text { значения),\% }\end{array}$ & 83,7 & 84,3 & 84,3 & 84,8 & 86 \\
\hline
\end{tabular}

Источни:к [15].

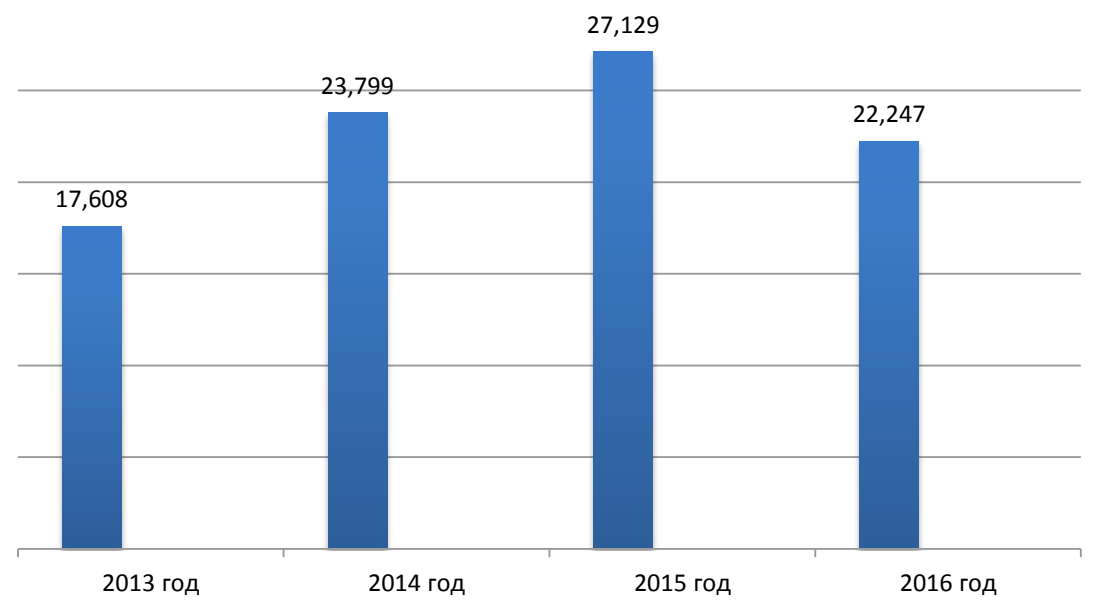

Рисунок 1. Исполнение бюджетных обязательств, млн руб. Источник: [15].

На рисунке 2 представлена структура выполненных дорожных работ по видам.

Развитие дорожного комплекса региона невозможно рассматривать изолированно от развития его элементов [8, 13] (Zaynullina, Sirazetdinov, Galyaviev, 2017; Medyanik, 2017) и различных предприятий и инфраструктур смежных отраслей [18] (Romanova, 2018). В связи с этим на сегодняшний день разрабатываются наиболее эффективные пути реализации стратегических целей инновационной деятельности [19] (Ustinova, Nizamova, Virtsev, 2017). В республике активно реализуется План совместных дейст- 

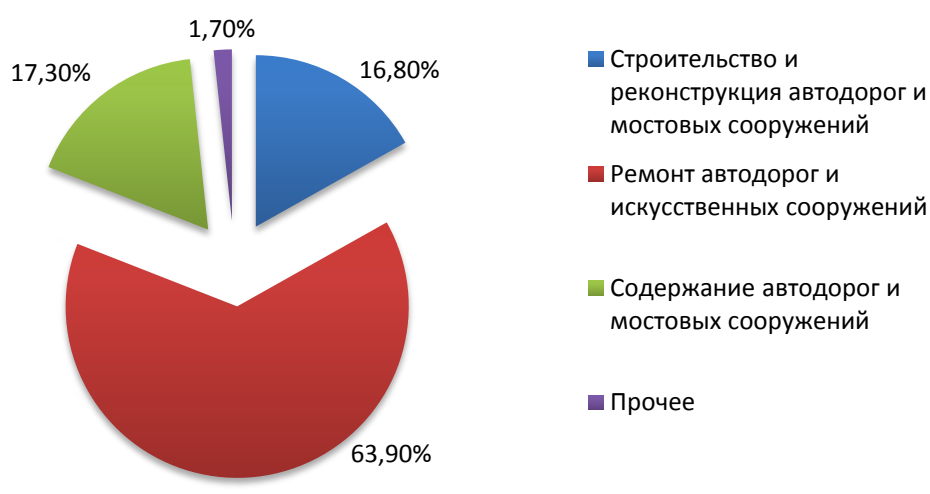

Рисунок 2. Структура дорожных работ в РТ за 2013-2016 года Источник: [15].

вий с ОАО «РОСНАНО» по стимулированию спроса на инновационную, в том числе нанотехнологическую, продукцию предприятиями дорожно-транспортного комплекса. Соглашением о сотрудничестве Республики Татарстан с OAO «POCHAHO» и Фондом инфраструктурных и образовательных программ на территории республики предусматривается реализация федеральных инновационных пилотных проектов «Инновационная дорога» и «Электрический транспорт». В рамках проекта «Инновационная дорога» планируются инновационное проектирование, строительство и ввод в эксплуатацию ряда пилотных участков автодорог с использованием современных инновационных материалов и технологий.

\section{Перспективы развития дорожных работ}

\section{на основе инновационных технологий}

Росавтодор утвердил комплекс технических мер для увеличения срока службы дорожных одежд, увеличив количество применяемых инноваций и финансирование работ по содержанию дорожной сети [20]. Если в 2012 г. применялось 212 инновационных технологий, то сегодня порядка шестисот. Инновационные технологии повышают устойчивость дороги к нагрузкам, в том числе от грузового транспорта, и к климатическим факторам. В России при строительстве автодорог требуются более сложные инженерные решения, чем во многих зарубежных странах. Большая толщина нижних слоев основания в российских проектах обеспечивает морозоустойчивость полотна: согласно национальным стандартам, общая толщина типовых дорожных одежд в России в среднем на 25\% больше, чем в Китае, и на 50\% превышает американские нормативы. Росавтодор и фонд «Сколково» заключили соглашение о сотрудничестве, предполагающее совместную работу по внедрению инноваций в дорожное строительство. В рамках сотрудничества стороны будут вести комплексную работу по поддержке перспективных инновационных проектов и содействовать их дальнейшему 
продвижению. Одним из направлений сотрудничества станет реализация современных образовательных программ, в том числе по внедрению в дорожную отрасль методов проектного управления. Кроме того, Росавтодор и «Сколково» смогут создавать научно-технические советы и рабочие группы, участники которых будут готовить рекомендации по внедрению передовых технологий. Ожидается, что применение инновационных технологий при ремонте дорог в России позволит экономить 14 млрд руб. ежегодно.

\section{Заключение}

Дорожно-строительный комплекс - это многоотраслевая структура, объединяющая подрядные, проектные и специализированные организации, предприятия строительной индустрии, транспортной логистики, инженерной инфраструктуры и многие другие. Система управления инновациями включает обоснование и выбор проектных решений, планирование, организацию, контроль и анализ инновационного процесса. Она охватывает все этапы: научные исследования, опытно-конструкторские разработки, экспериментальное строительство для подготовки массового внедрения, оценку полученного эффекта. Программа экспериментального строительства насчитывает ряд успешно реализованных проектов, где применение новых материалов и технологий принесло положительный эффект и которые могут применяться серийно в плановом порядке. В связи с этим целесообразность применения инновационных технологий при строительстве, реконструкции и содержании автомобильных дорог в каждом конкретном случае обосновывается с технической и экономической точки зрения.

\section{ИСТОЧНИКИ:}

1. Абдуханова Н.Г., Кульков А.А. Организационно-экономический механизм государственно-частного партнерства при реализации лофт-проекта // Российское предпринимательство. - 2017. - № 23. - c. 3837-3846. - doi: 10.18334/rp.18.23.38608.

2. Белай О.С., Мухаметзянова Д.Д. Структурный аспект инновационной деятельности // Креативная экономика. - 2014. - № 12(96). - с. 23-30.

3. Гимадиева Л.Ш. Промышленное строительство Татарстана: основные тенденции // Политематический сетевой электронный научный журнал Кубанского государственного аграрного университета. - 2017. - № 129. - с. 1235-1245. - doi: 10.21515/1990-4665-129-088 .

4. Гужов В.В. Стратегические направления совершенствования инновационной политики в транспортной отрасли // Транспортное дело России. - 2013. - № 3. - с. 5-8. - url: https://elibrary.ru/item.asp?id=20173204.

5. Дудин М.Н., Толмачев О.М. Практика внедрения инновационных технологий в строительной отрасли // Вопросы инновационной экономики. - 2017. - № 4. c. 407-416. - doi: 10.18334/vinec.7.4.38626. 
6. Жуков Е.А., Ильин С.В. Модернизация дорожного хозяйства России на основе инновационных технологий // МИР (Модернизация. Инновации. Развитие). - 2017. - № 2(30). - с. 196-202.

7. Загидуллина Г.М., Зайнуллина Д.Р., Мавлютова А.Р., Сиразетдинова Э.Р. Реализация инновационных проектов как основа экономического развития // Российское предпринимательство. - 2017. - № 23. - с. 3725-3738. - doi: 10.18334/rp.18.23.38612.

8. Зайнуллина Д.Р., Сиразетдинов Р.М., Галявиев Б.И. Теоретические предпосылки развития инновационной политики Республики Татарстан // Российское предпринимательство. - 2017. - № 23. - с. 3739-3750. - doi: 10.18334/rp.18.23.38614.

9. Ильина Е.В., Курзина И.М. Развитие промышленности строительных материалов с учетом использования рынка информационных услуг // Управление экономическими системами: электронный научный журнал. - 2017. - № 9(103). - с. 28.

10. Клещева О.А. Особенности расчета эффективности инноваций с учетом затрат на охрану окружающей среды // Вопросы инновационной экономики. - 2017. - № 4. c. 381-390. - doi: 10.18334/vinec.7.4.38622.

11. Клещева О.А. Развитие автодорожного строительства в Республике Татарстан // Вестник экономики, права и социологии. - 2015. - № 3. - с. 49-52.

12. Лапин Р.П. Оценка густоты дорожной сети // Молодой ученый. - 2016. - № 12(116). - c. 311-314.

13. Медяник Ю.В. Рынок инжиниринговых услуг в России: проблемы и перспективы развития // Российское предпринимательство. - 2017. - № 24. - c. 4221-4234. - doi: 10.18334/rp.18.24.38595.

14. Министерство транспорта Российской Федерации. [Электронный ресурс]. URL: https://www.mintrans.ru ( дата обращения: 04.10.2018 ).

15. Отчет счетной палаты Республики Татарстан о результатах аудита эффективности использования государственных средств, выделенных в 2013-2016 годы на проведение дорожных работ в Республике Татарстан. Xn--j1ahjm. [Электронный ресурс]. URL: http://xn--j1ahjm.xn--p1ai/downloads/Finkontrol/Otchet_Audit_efffektivnosti_ Tatarstan_06_2017.pdf.

16. Рахматуллина Е.С. Экономическая взаимосвязь строительного и энергетического комплексов// Управление экономическими системами: электронный научный журнал. - 2015. - № 12(84). - с. 40.

17. Рожков В.Л., Зайнуллина Д.Р. Критический анализ перспектив инновационного развития строительной отрасли Республики Татарстан // Российское предпринимательство. - 2016. - № 21. - с. 2911-2922. - doi: 10.18334/rp.17.21.36934.

18. Романова А.И. Роль инновационных территориальных кластеров в реализации инновационной политики Республики Татарстан // Сибирская финансовая школа. - 2018. - № 2(127). - c. 94-100.

19. Устинова Л.Н., Низамова А.Ш., Вирцев М.Ю. Алгоритм прогнозирования стратегии инновационной деятельности предприятий // Экономический анализ: теория и практика. - 2017. - № 11(470). - c. 2111-2122. - doi: 10.24891/ea.16.11.2111 . 
20. Федеральное дорожное агентство. Rosavtodor. [Электронный ресурс]. URL: http:// www.rosavtodor.ru ( дата обращения: 03.10.2018).

21. Шагиахметова Э.И., Мухаррамова Э.Р., Кафиатуллина М.А. Конкурентный анализ предприятий промышленности строительных материалов // Российское предпринимательство. - 2017. - № 14. - с. 2153-2170. - doi: 10.18334/rp.18.14.38122.

\section{REFERENCES:}

Abdukhanova N.G., Kulkov A.A. (2017). Organizatsionno-ekonomicheskiy mekhanizm gosudarstvenno-chastnogo partnerstva pri realizatsii loft-proekta [Organizational and economic mechanism of public-private partnership in the implementation of loft-project]. Russian Journal of Entrepreneurship. 18 (23). 3837-3846. (in Russian). doi: $10.18334 /$ rp.18.23.38608.

Belay O.S., Mukhametzyanova D.D. (2014). Strukturnyy aspekt innovatsionnoy deyatelnosti [Structural aspect of innovative activities]. Creative economy. (12(96)). 23-30. (in Russian).

Dudin M.N., Tolmachev O.M. (2017). Praktika vnedreniya innovatsionnyh tekhnologiy $\mathrm{v}$ stroitelnoy otrasli[Introduction of innovative technologies in the construction industry]. Russian Journal of Innovation Economics. (4). 407-416. (in Russian). doi: 10.18334/vinec.7.4.38626.

Gimadieva L.Sh. (2017). Promyshlennoe stroitelstvo Tatarstana: osnovnye tendentsii [Industrial construction of tatarstan: main trends]. Scientific Journal of KubSAU. (129). 1235-1245. (in Russian). doi: 10.21515/1990-4665-129-088 .

Guzhov V.V. (2013). Strategicheskie napravleniya sovershenstvovaniya innovatsionnoy politiki $v$ transportnoy otrasli [Strategic directions of perfection an innovative policy in transport branch]. Transport business in Russia. (3). 5-8. (in Russian).

Ilyina E.V., Kurzina I.M. (2017). Razvitie promyshlennosti stroitelnyh materialov s uchetom ispolzovaniya rynka informatsionnyh uslug [The development of the building materials industry, taking into account the use of the information services market]. Management of economic systems: scientific electronic journal. (9(103)). 28. (in Russian).

Klescheva O.A. (2015). Razvitie avtodorozhnogo stroitelstva v Respublike Tatarstan [Development of Highway Construction in the Republic of Tatarstan]. The Review of Economy, the Law and Sociology. (3). 49-52. (in Russian).

Klescheva O.A. (2017). Osobennosti rascheta effektivnosti innovatsiy s uchetom zatrat na okhranu okruzhayuschey sredy [Peculiarities of calculating the efficiency of innovations, taking into account costs of environmental protection]. Russian Journal of Innovation Economics. 7 (4). 381-390. (in Russian). doi: 10.18334/ vinec.7.4.38622. 
Lapin R.P. (2016). Otsenka gustoty dorozhnoy seti [Assessment of the density of the road network]. The young scientist. (12(116)). 311-314. (in Russian).

Medyanik Yu.V. (2017). Rynok inzhiniringovyh uslug v Rossii: problemy i perspektivy razvitiya [Engineering services market in Russia: problems and development prospects]. Russian Journal of Entrepreneurship.18 (24). 4221-4234. (in Russian). doi: 10.18334/rp.18.24.38595.

Rakhmatullina E.S. (2015). Ekonomicheskaya vzaimosvyaz stroitelnogo i energeticheskogo kompleksov[Economic interrelation of building and energy complexes]. Management of economic systems: scientific electronic journal. (12(84)). 40. (in Russian).

Romanova A.I. (2018). Rol innovatsionnyh territorialnyh klasterov v realizatsii innovatsionnoy politiki Respubliki Tatarstan [Role of innovative territorial clusters in realization of innovative policy of the republic of tatarstan]. Siberian Financial School. (2(127)). 94-100. (in Russian).

Rozhkov V.L., Zaynullina D.R. (2016). Kriticheskiy analiz perspektiv innovatsionnogo razvitiya stroitelnoy otrasli Respubliki Tatarstan [Critical analysis of the prospects of innovational development of the construction industry in the Republic of Tatarstan]. Russian Journal of Entrepreneurship. 17 (21). 2911-2922. (in Russian). doi: 10.18334/rp.17.21.36934.

Shagiakhmetova E.I., Mukharramova E.R., Kafiatullina M.A. (2017). Konkurentnyy analiz predpriyatiy promyshlennosti stroitelnyh materialov [Competitive analysis of enterprises of construction materials industry]. Russian Journal of Entrepreneurship. 18 (14). 2153-2170. (in Russian). doi: 10.18334/rp.18.14.38122.

Ustinova L.N., Nizamova A.Sh., Virtsev M.Yu. (2017). Algoritm prognozirovaniya strategii innovatsionnoy deyatelnosti predpriyatiy [An algorithm to forecast a strategy of innovative activities of enterprises].Economic analysis: theory and practice. 16 (11(470)). 2111-2122. (in Russian). doi: 10.24891/ea.16.11.2111 .

Zagidullina G.M., Zaynullina D.R., Mavlyutova A.R., Sirazetdinova E.R. (2017). Realizatsiya innovatsionnyh proektov kak osnova ekonomicheskogo razvitiya [Implementation of innovation projects as a basis for economic development]. Russian Journal of Entrepreneurship. 18 (23). 3725-3738. (in Russian). doi: 10.18334/rp.18.23.38612.

Zaynullina D.R., Sirazetdinov R.M., Galyaviev B.I. (2017). Teoreticheskie predposylki razvitiya innovatsionnoy politiki Respubliki Tatarstan [Theoretical prerequisites for development of innovation policy of the Republic of Tatarstan]. Russian Journal of Entrepreneurship. 18 (23). 3739-3750. (in Russian). doi:10.18334/rp.18.23.38614.

Zhukov E.A., Ilyin S.V. (2017). Modernizatsiya dorozhnogo khozyaystva Rossii na osnove innovatsionnyh tekhnologiy [Modernization of the road infrastructure of Russia based on innovative technologies]. MIR (Modernization. Innovation. Research). 8 (2(30)). 196-202. (in Russian). 